\title{
Memoria: la curiosa historia de un código cultural ${ }^{*}$
}

\author{
Steve J. Stern ${ }^{* *}$ \\ University of Wisconsin-Madison, Estados Unidos
}

DOI: $10.22380 / 2539472 X .1048$

\section{La palabra código}

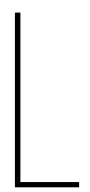

a memoria es un código cultural de nuestros tiempos. Es una palabra que tiene resonancia por tratarse de un imperativo de no olvido —no olvidar a las personas destruidas por regímenes de crueldad y violencia de masas, no olvidar a los sobrevivientes y sus derechos a la reparación en el presente, no olvidar que los arquitectos de la atrocidad del Estado agravaron el daño a través de la negación y el encubrimiento, no olvidar la verdad y la responsabilidad por los crímenes contra los derechos humanos-. La memoria importa sobre todo porque los regímenes de atrocidad son también regímenes de eufemismo y desinformación. La desinformación fomenta la indiferencia y el olvido; socava la responsabilidad.

En resumen, la "memoria" evoca la lección moral de los derechos humanos y la idea asociada del "nunca más". Expresa una conciencia de lucha contra el terror de Estado y los proyectos de exterminio o, en un sentido más positivo, un despertar a los valores. En algunos casos, la memoria también evoca un imperativo de recordar y rechazar los proyectos asesinos de actores no estatales, como la guerra civil en Perú durante los años ochenta y noventa, en la que el Estado ejerció una cruel violencia contra los civiles pese a que los insurgentes de Sendero Luminoso fueron los responsables de la mayoría de los asesinatos. Un

Traducción de "Memory: The Curious History of a Cultural Code Word", publicado originalmente en Radical History Review 2016 (124): 117-128. El Instituto Colombiano de Antropología e Historia agradece a Duke University Press por haber otorgado los derechos de traducción y reimpresión de este manuscrito para esta edición de la Revista Colombiana de Antropología. La revista realizó correcciones menores a la versión original para adaptar el texto a las normas actuales de la lengua española, y con el fin de adecuarlo a las normas formales de la RCA, que se rige por The Chicago Manual of Style, 16 th. [N. de la e.] El artículo está sujeto a derechos de autor: Copyright, 2016, MARHO: The Radical Historians Organization, Inc. All rights reserved.

Profesor emérito del Departamento de Historia de la University of Wisconsin-Madison. Su reconocida trayectoria académica se ha enfocado en las respuestas amerindias al colonialismo, las relaciones de género, la economía política, la aquiescencia social y la rebeldía, y los recuerdos de trauma y violencia política en los Andes, México y Chile. [N. de la e.] 
lado oculto de la historia moderna es el surgimiento de proyectos de purificación social y política, cuyo alcance efectivo y organización sistemática, así como la crueldad violenta y la demonización ideológica, son tan extremos que parecen exceder los límites de lo imaginable.

Ese lado oculto también ha producido como corolario un doloroso despertar, al menos por parte de algunos actores sociales. La lección moral clave es que los derechos humanos son inviolables y su violación es inolvidable. El Estado no puede utilizar los estados de emergencia social o política como pretexto para destruir la integridad física y psíquica de las personas a través de actos de extrema crueldad y violencia, como la tortura, el asesinato sumario, el secuestro que conduce a la desaparición permanente, la agresión sexual o la ejecución simulada. Tampoco pueden hacerlo los insurgentes. El contexto no puede justificar dejar de lado los derechos humanos fundamentales, ni siquiera los de aquellos ciudadanos redefinidos como presunto enemigo interno. Tampoco puede justificar dejar de lado la memoria y la responsabilidad después del hecho¹.

Asociaciones como las mencionadas se han convertido en un lugar común en la cultura mundial, aunque con una intensidad desigual por región y en el tiempo. Han sido importantes en países influyentes de América Latina y África, como Chile y Sudáfrica, Alemania en el norte global, y en Estados Unidos (antes del 9/11). Lo que estos países tienen en común es que en algún momento sufrieron un juicio político, conflictivo y culturalmente desgarrador, con responsabilidad o complicidad en un régimen de atrocidades propio del siglo XX. Igualmente importante, tales asociaciones también han surgido entre los actores sociales a un nivel supranacional: redes transnacionales de defensa jurídica y organizaciones no gubernamentales, como Amnistía Internacional, Human Rights Watch y el Centro Internacional de Justicia Transicional. Estas asociaciones han surgido, quizás en menor medida, entre las entidades interestatales formales, como los comités de derechos humanos de las Naciones Unidas, la Corte Penal Internacional y la Corte Interamericana de Derechos Humanos. En tales organizaciones la identidad es cosmopolita y la misión invoca valores trascendentes. Esos valores pueden requerir la acción de los “ciudadanos del mundo" supranacionales, ya sea para avergonzar y constreñir a un Estado infractor, para rastrear y señalar a los responsables que han eludido la justicia o para ayudar a los actores estatales y de la sociedad civil a lograr una transición posatrocidad legítima y sostenible².

1 Para Sendero Luminoso y su tratamiento cultural, véanse Degregori (2012) y Milton (2014). Para modernidad y atrocidad, véanse Bartov (2000) y Franco (2013).

2 Para conocer las tendencias mundiales y los análisis multiescalares, véanse Sikkink (2011), Keck y Sikkink (1998) y Huneeus (2013). 
Estos desarrollos significan que, aunque el Holocausto ha sido un foco clave en la política cultural de la memoria desde finales del siglo XX, el valor atribuido a la memoria ya no se limita a las reflexiones sobre él. Damos por sentado que la "memoria” es un imperativo moral en un ámbito más amplio de pasados dentro del presente y que es estratégica para la construcción de los derechos humanos y la democracia después del terror estatal. Este es el caso, pese a que los estudiosos observan que la batalla para recordar no se reduce únicamente a un conflicto dicotómico entre la memoria y el olvido, ni el recuerdo de la persecución se alinea siempre con la promoción de los derechos humanos. La lucha no se trata únicamente de determinar los hechos críticos que la verdad oficial niega, sino también su significado. ¿Qué aprendemos de una experiencia catastrófica? Que la batalla se da entre distintos marcos de memoria, cada uno enfocado selectivamente en qué debe ser recordado y por qué. A pesar de tales advertencias académicas, la asociación de la "memoria" con la lucha por los derechos humanos y la democracia - y con la batalla contra el olvido- perdura entre los actores sociales y es legítima. Dada la negación y la desinformación por parte de los regímenes de dictadura que arrasaron Sudamérica en la década de los setenta, y de su despliegue de misteriosos secuestros que "desaparecieron" de manera permanente a las víctimas y las convirtieron en personas sin rastro, la idea de “memoria” como un valor sagrado llegó a tener una influencia especialmente poderosa en los campos que presionaban por los derechos humanos y la transición democrática ${ }^{3}$.

La impronta de la memoria como una palabra clave evocadora de verdad y justicia, y de modo más general, de una cultura de derechos humanos sin la cual la democracia carecería de fundamento, se hizo evidente durante la lenta y difícil transición de Chile después de la dictadura de Augusto Pinochet (1973-1990). Se consideran aquí tres hitos. En 1990, mientras el recién elegido presidente civil Patricio Aylwin (presidente desde 1990 hasta 1994) anunciaba la creación de una comisión de la verdad, la sed cultural por documentar la verdad oculta de la violencia estatal apareció en la lista de los más vendidos. De hecho, el título más vendido sobre la historia de la Vicaría de la Solidaridad, un actor central en la lucha por los derechos humanos bajo el mando militar, fue Chile: la memoria prohibida (Ahumada et al. 1989). La memoria era la verdad "prohibida" que no nos habían permitido oír durante mucho tiempo ${ }^{4}$.

3 Para marcos sobre memoria en competencia, véanse Jelin (2002), Stern (2004) y Todorov (2002).

$4 \quad$ Sobre best sellers, véase Stern (2010). 
Siete años después, muchos líderes políticos de la coalición gobernante de centro-izquierda parecían intimidados tanto por la continuidad en el poder de Pinochet y su base social, como por la inmanejable división de los derechos humanos. Habían perdido la voluntad de impulsar nuevas iniciativas de verdad y justicia. Una conmovedora película de Patricio Guzmán, Chile: la memoria obstinada, de 1997, sobre el destino de los sobrevivientes del golpe y la generación de jóvenes posdictadura en el nuevo y olvidadizo Chile de los noventa, causó una pequeña conmoción. Para muchos activistas de la sociedad civil y escépticos desilusionados por el repliegue de los derechos humanos y la sensación de que el tabú cultural había resurgido para sofocar la discusión sobre el pasado en el presente, la película documentaba la herida de una transición que se había extraviado. También anunciaba que esa amnesia resultaría infructuosa. Chile: la memoria obstinada sugirió que la memoria - ya fuera el sueño de igualdad que inspiró a las bases de Salvador Allende o la violencia salvaje para destruir a los soñadores - era una experiencia demasiado “obstinada” para ser desechada. Los recuerdos de la década de los setenta fueron persistentes y tercos: tan fundamentales y traumáticos para ser negados para siempre. Eran la verdad profunda justo debajo de la plácida superficie (Guzmán 1998) ${ }^{5}$.

Hacia el 2003 un ambiente de memoria más abierto e insistente había resurgido en Chile. En parte esto fue consecuencia de la detención de Pinochet en 1998 en Londres por crímenes de lesa humanidad, pero también fue el resultado de nuevas iniciativas y movilizaciones sociales en torno a los derechos humanos en Chile e, igualmente, como respuesta a la proximidad de los treinta años del golpe de Estado ocurrido el 11 de septiembre de 1973. En agosto, el presidente socialista Ricardo Lagos (presidente entre el 2000 y el 2006) anunció una nueva iniciativa de comisión de la verdad. La anterior comisión de la verdad (1990-1991) se había centrado en las ejecuciones y desapariciones. No se enfocó en la tortura, excepto en los casos que culminaron en la muerte de la víctima. Ahora, una nueva comisión (conocida como la Comisión Valech, llamada de ese modo por su presidente, el obispo retirado, monseñor Sergio Valech, quien había sido el último jefe de la Vicaría de la Solidaridad) se centraría en el encarcelamiento político y en la tortura como tal. La magnitud de la tortura en el Chile de Pinochet fue enorme; la cantidad de víctimas capaces y dispuestas a testificar ascendería a decenas de miles. Significativamente, en este punto el poder de la memoria como un código cultural se había abierto camino en una expresión de una iniciativa estatal. Lagos invocó la memoria en el título de su iniciativa: “No hay mañana sin ayer”. En 
el 2004 su discurso a la nación con el resumen del informe y su respuesta a este invocó una idea similar: "Para nunca más vivirlo, nunca más negarlo” (Stern 2010).

La potencia de la memoria como un código cultural persistió, como una consigna entre activistas de la sociedad civil en protesta por la deficiencia de la política estatal sobre derechos humanos tanto como un discurso estatal para abordar la herida de las violaciones de derechos humanos. En el 2005, por ejemplo, un colectivo de base emitió una crítica al informe sobre tortura de la Comisión Valech. De manera significativa, el grupo se llamó a sí mismo Colectivo de Memoria Histórica (el nombre completo, después de que un importante centro de tortura fuera recuperado como un lugar de memoria para promover el trabajo de derechos humanos, fue Colectivo de Memoria Histórica Corporación José Domingo Cañas). El colectivo consideró que el mandato de la Comisión Valech era demasiado restringido. Se dedicó a investigar la historia y las consecuencias de los allanamientos militares que ocurrieron en los barrios de la clase trabajadora y barrios marginales/chabolas (poblaciones). Fuerzas militares y policiales ocuparon las comunidades, cercaron a un gran número de prisioneros que fueron retenidos en espacios públicos convertidos en corrales de encierro durante algunos días, y les infligieron crueldades físicas y mentales tan extremas que el grupo argumentó que equivalían a tortura. Este grupo también investigó fuentes de prensa y archivos de derechos humanos, complementó la investigación documental con trabajo de campo, considerando en su universo 359 allanamientos en 113 poblaciones. El número estimado de víctimas era enorme. En 16 poblaciones donde todos los varones mayores de 15 años fueron violentamente detenidos durante un día o dos, y para las cuales había datos censales confiables, las víctimas directamente afectadas ascendieron aproximadamente a 98.000 personas (Colectivo de Memoria Histórica Corporación José Domingo Cañas 2005).

Para el 2010, cuando la socialista Michelle Bachelet (presidente de 2006 a 2010 y de 2014 a 2018) inauguró el más impresionante y concurrido Museo de los Derechos Humanos de América Latina como legado distintivo de su primera presidencia, el poder de la memoria como una palabra código fue obvia. El nombre Museo de la Memoria y los Derechos Humanos subrayó el punto: los derechos humanos eran un valor fundamental, pero la memoria era su prerrequisito ${ }^{6}$. Todos los ejemplos anteriores, sin embargo, no abordan un misterio histórico. Evidencian que la lucha por la memoria importó durante la transición democrática y que el lenguaje de la memoria demostró ser tan fuerte y resonante que eventualmente se institucionalizó en el trabajo de memorialización del Estado. Memoria 
y derechos humanos estaban estrechamente asociados, y los derechos humanos sirvieron como un punto de partida fundamental - un contraste clave con la dictadura-para la construcción de un Estado democrático legítimo. Lo que los ejemplos anteriores no muestran es cuándo un lenguaje de memoria que lucha contra el olvido, y su estrecha asociación con los derechos humanos, comenzó a afianzarse. Después de todo, existían otros lenguajes de asociación, en particular los de la "verdad" y la "justicia” como búsquedas gemelas que fueron negadas constantemente por el mundo imaginado y las narrativas prefabricadas de la dictadura. Estos eran términos de valor moral que tuvieron una gran repercusión. En un sentido real, durante la transición democrática la memoria como un código cultural vino a representar tres ideas - derechos humanos, verdad y justicia-y las vinculó a las luchas contra el olvido, es decir, contra el olvido diseñado.

\section{El misterio: ¿la lucha por la memoria antes de la memoria?}

El misterio se profundiza si pensamos en Salvador Allende, particularmente en su improvisado pero elocuente último discurso radial dirigido a la nación el 11 de septiembre de 1973, día en que la fuerza aérea chilena bombardeó el palacio presidencial. Allende entendió que el golpe provocaría una lucha sobre cómo recordar los hechos y significados de lo que sucedió. Su discurso se convirtió en parte de esa lucha. Pero el referente clave —el lenguaje disponible para él—era la historia, no la memoria. Frente a la traición de los militares y policías de más alto rango dijo: "yo no voy a renunciar”. Explicó:

Colocado en un tránsito histórico, pagaré con mi vida la lealtad del pueblo. Y les digo que tengo la certeza que la semilla que entregáramos a la conciencia digna de miles y miles de chilenos no podrá ser segada definitivamente. Tienen la fuerza, podrán avasallarnos, pero no se detienen los procesos sociales ni con el crimen ni con la fuerza. La historia es nuestra y la hacen los pueblos.? (Allende 1973, 1:18)

Tan pronto Allende se despidió de su base social, la lucha por la memoria continuó tomando la forma de un reclamo ante la historia. Allende agradeció a

\footnotetext{
7 El enlace consultado originalmente (www.lanacion.cl/lea-y-escucha-el-ultimo-discurso-deallende/noticias/2013-09-10/184948.html) está inactivo. Para escuchar el discurso completo, veáse https://www.youtube.com/watch?v=xZeEfXjTNu4 [N. de la e.]
} 
los trabajadores que depositaron su confianza "en un hombre que solo fue intérprete de grandes anhelos de justicia” (Allende 1973, 2:19). También agradeció a las mujeres que como campesinas, trabajadoras y madres lo apoyaron (3:34); al sector patriótico de profesionales de clase media que no sucumbieron a la defensa vitriólica del privilegio capitalista; y a los jóvenes que "cantaron, entregaron su alegría y su espíritu de lucha” (4:11). Había cumplido su palabra de respetar la ley y la Constitución. Muchos chilenos ahora sufrirían persecución, pero aquellos entre quienes se había fomentado el fascismo y el terror no escaparían a un cálculo: "la historia los juzgará” (4:48).

Es muy significativo que cuando Allende mencionó la memoria como tal, lo hizo de modo personal en el sentido común de la palabra. La memoria aún no era un concepto trascendente, una consigna o un código cultural. "Siempre estaré junto a ustedes. Por lo menos mi recuerdo será el de un hombre digno que fue leal con la patria” (5:07).

El lenguaje de la memoria no existía como un código político o cultural en el Chile de 1973. Allende se basó en los lenguajes de su tiempo. La categoría social del “trabajador” era icónica —culturalmente familiar y políticamente indispensable - y figuraba de modo prominente en el discurso. Durante su presidencia, un tiempo de luchas tumultuosas para promover o revertir el control obrero y campesino sobre las fábricas y fundos (latifundios), respectivamente, clase y conflicto de clase también resonaban como un lenguaje de la experiencia. Pero, aunque se desarrolló una feroz batalla en torno a cómo recordar un tiempo extraordinario que podría terminar catastróficamente, el lenguaje de la lucha por la memoria como una experiencia y un valor consecuentes aún no se había materializado.

Podríamos decir entonces que una lucha por la memoria se materializó y desempeñó un papel importante dentro de un conflicto social muy grave, a pesar de que el lenguaje cultural de la "memoria” aún no se había concretado. Para entender esta paradoja puede ser útil recordar un problema más o menos análogo analizado por Edward P. Thompson (1978), el gran historiador de la clase obrera inglesa. Al considerar la clase, la cultura plebeya y el continuo control cognitivo del paternalismo a pesar de una erosión del vínculo alta burguesía - plebeyos durante el siglo XVIII en Inglaterra, antes de la consolidación del trabajo libre y de la Revolución Industrial capitalista como proceso experiencial en el siglo XIX, Thompson se enfrentó con qué venía primero. Se preguntó si las relaciones propias de la "lucha de clases" podrían desplegarse con fuerza pese a permanecer encerradas dentro de conceptos mentales y mediaciones sociales de un régimen moribundo. El autor pensó que algo así sucedió en la Inglaterra del siglo XVIII, 
una sociedad que parecía encarnar la "lucha de clases sin clase”. Argumentó que es la experiencia de la lucha lo que produce nuevas posibilidades cognitivas. "Se ha prestado demasiada atención teórica... a la 'clase'. De hecho, la lucha de clases es el concepto previo, así como el más universal” (Thompson 1978, 149)².

En este sentido, Allende entendió el lenguaje de la clase y de la lucha de clases. Lo que aún no había surgido, incluso en medio de una agudizada lucha sobre cómo recordar, era la memoria como un lenguaje de la experiencia.

\section{Memoria como descubrimiento}

No fue hasta finales de los años setenta y principios de los ochenta que la memoria comenzó a surgir como un código cultural en Chile. De modo significativo, olvido se cristalizó primero como una palabra estratégica y, más tarde, memoria como su antítesis. Los actores sociales, pioneros del nuevo lenguaje, eran víctimas-sobrevivientes. Parientes de los desaparecidos, sobre todo - pero no exclusivamente- mujeres, se dieron cuenta de que su propia tragedia familiar, su propia búsqueda de un ser querido desaparecido, pertenecía a un patrón más grande de detenciones misteriosas. Las detenciones se convirtieron en una desaparición, con la negación del conocimiento o responsabilidad por parte del Estado. En respuesta a esta realidad, los familiares se organizaron en una comunidad de apoyo y activismo conocida como la Agrupación de Familiares de Detenidos Desaparecidos (AFDD). La membresía a la AFDD de Santiago, la rama más influyente, superó los trescientos miembros a finales de 1975 y aumentó otra vez cuando la policía secreta, hacia 1976, atacó a comunistas en una nueva ola de represión. Junto con otros grupos de derechos humanos, incluida la Vicaría de la Solidaridad de la Iglesia católica en Santiago, los activistas de la AFDD insistieron en descubrir la verdad sobre sus familiares desaparecidos y en que el Estado entregara información veraz sobre su destino ${ }^{9}$.

Para los activistas de la AFDD y sus partidarios, la "memoria” fue un descubrimiento, no un punto de partida evidente. Daba testimonio de un proceso de aprendizaje, a la vez político y cultural, en tiempos de ordalías. El cambio de

\footnotetext{
8 En la versión original: "Far too much theoretical attention... has been paid to 'class' and far too little to 'class-struggle.' Indeed, class struggle is the prior, as well as the more universal, concept” (Thompson 1978, 149). [N. de la e.]
} 
estrategias y del léxico de la lucha comenzó hacia 1977-1978. Frustrados por un muro de negación construido por el Estado, que no solo abarcaba el Poder Ejecutivo sino también el Poder Judicial, los familiares pensaron que había llegado el tiempo de una acción más agresiva en la esfera pública. La forma de aproximación anterior - peticiones judiciales cuidadosamente preparadas y documentadas, boletines confidenciales sobre la verdad escondida que fueron puestos en circulación por la Vicaría de la Solidaridad a una red restringida, revistas alternativas solidarias también respaldadas por la Vicaría - no fue suficiente. La búsqueda de nuevas estrategias, en diálogo pero también en cierta tensión con la Vicaría de la Solidaridad y la Iglesia católica, había comenzado a finales de 1976. Hacia 1977-1978 la decisión de presionar más fuerte en la esfera pública adoptó una forma dramática: protestas callejeras, huelgas de hambre, llamamientos de acción directa a las Naciones Unidas.

Las nuevas acciones provocaron consternación y nuevos lenguajes de reclamo y movilización. Aquí comenzamos a encontrar la palabra olvido cristalizándose como una forma de codificar de qué se trataba la lucha. Pero, como veremos, esa cristalización no sucedió de una sola vez. El 14 de junio de 1977, 26 parientes de desaparecidos ocuparon las oficinas chilenas de la Comisión Económica para América Latina de la ONU y se lanzaron a una huelga de hambre. En 1976, 31 de sus 34 familiares desaparecidos habían sido capturados recientemente. ¡Si se los hubiera encontrado a tiempo, aún podrían estar vivos! El simbolismo de género de esta lucha desesperada fue sorprendente: 8 de 10 parientes desaparecidos eran hombres; 9 de 10 personas en la huelga de hambre eran mujeres. Esta fue una lucha de madres, esposas y hermanas para encontrar a sus seres queridos. La publicidad y la presión fueron sustanciales: una masa solidaria gigante en Santiago, las huelgas de hambre solidarias en Europa, negociaciones entre el secretario general de las Naciones Unidas, Kurt Waldheim, y el embajador chileno Alfredo Canales Márquez. Los familiares acordaron suspender la huelga a cambio de un prometido informe para la ONU con datos confiables sobre las personas desaparecidas. En una carta pública de seguimiento dirigida a Pinochet el 20 de julio de 1977, los familiares expresaron, "hemos agotado" todos los canales normales de reparación. Los procedimientos legales y administrativos y los pedidos de habeas corpus no habían podido destruir "el anillo de silencio" que rodeaba a sus seres queridos. Temían que "exista un encubrimiento deliberado de una realidad dramática con una capa de olvido"10. Arzobispado de Santiago (en adelante, FAV). 
Una capa de olvido. El tema del olvido no se desvaneció. Hacia 1978, huelgas de hambre y otras acciones provenientes de una variedad de actores presionaron cada vez más sobre los temas de derechos humanos. Para Pinochet y la Junta Militar, las presiones convergieron con otras tensiones, incluida una lucha por el poder entre Pinochet y su rival de la Junta, el comandante de la Fuerza Aérea, general Gustavo Leigh; una crisis o casi guerra con Argentina que requirió la mediación del papa Juan Pablo II y la tensión aguda con Estados Unidos por cartas oficiales rogatorias, firmadas por el secretario de Estado, Cyrus Vance, y el fiscal general, Griffin Bell, así como el juez de distrito, William B. Bryant, en las que se solicitaba la extradición de testigos para declarar bajo juramento en la investigación en curso del juicio de los asesinatos de Orlando Letelier y Ronni Karpen Moffitt en 1976. Dichos asesinatos tuvieron lugar en Washington D. C. Letelier era el exembajador de Allende en Estados Unidos y Moffitt, su colega en el Institute for Policy Studies, y ciudadano estadounidense. La policía secreta chilena (Dirección de Inteligencia Nacional [DINA]) había orquestado el asesinato y su temido jefe, Manuel Contreras, informaba a Pinochet directamente. Pinochet sobrevivió a la crisis de 1978, en parte, al crear un gabinete civil-militar en abril y sacar a Leigh de la Junta en julio. El 19 de abril de 1978, el líder civil del nuevo gabinete, el ministro del Interior, Sergio Fernández, anunció un nuevo comienzo para Chile a través de la amnistía. Los tiempos de "guerra" habían pasado y el país estaba ahora en el camino hacia la institucionalización. El Decreto Ley 2191 de 1978 proporcionaría amnistía (con excepciones para algunos delitos comunes y en el caso Letelier) por actos criminales entre el 11 de septiembre de 1973 y el 10 de marzo de 1978. El decreto equivalía a la autoamnistía para los oficiales que temían la responsabilidad penal ante el aumento de la presión de los derechos humanos y el precedente establecido por el caso Letelier. Fernández presentó la amnistía como humanitarismo generoso, ahora que habían pasado los tiempos difíciles. Se presumía que incluiría prisioneros políticos. El Gobierno "no guarda rencores y sabe que el perdón y el olvido deben abrir nuevos caminos al país reunificado [patria]" (El Mercurio, abril de 1978) ${ }^{11}$. El olvido fue un bien positivo.

Esto era precisamente lo que temían los familiares de los desaparecidos: una política que asegurara la desaparición de las personas para siempre. Olvidar significaba encubrir. Así lo expresaron en una carta a Fernández una semana después: "Nuestros familiares no pueden perderse en el olvido". Igualmente importante fue la aún más dramática huelga de hambre que iniciaron en mayo. Sesenta y cinco familiares - todos excepto seis eran mujeres- ocuparon tres 
iglesias y la oficina del Fondo de las Naciones Unidas para la Infancia (Unicef). Huelgas de hambre solidarias estallaron no solo en Europa, Canadá y Estados Unidos, sino también en Chile, y no solamente en Santiago sino en Valparaíso y Concepción. Los huelguistas incluyeron personas religiosas, entre ellas sacerdotes católicos y miembros de la comunidad laica ${ }^{12}$.

La lucha contra el olvido intencional, respaldada por un decreto oficial y una amnistía, no produjo la información que los familiares esperaban. Tampoco derribó a Pinochet. El régimen continuó insistiendo en que la emergencia de la década de 1970 estaba cediendo a la institucionalización ordenada, a lo cual sobrevino una nueva Constitución en 1980. Lo que la lucha sí produjo fue el cambio de las estrategias de lucha y reflexión e implicó la evolución de un léxico de palabras clave para el campo de los derechos humanos. Ese léxico empezó a incluir no solo términos como verdad, justicia y derechos humanos, también comenzó a incluir olvido y memoria, una antítesis estratégica en el marco de una lucha de largo plazo.

De nuevo, los familiares de la AFDD fueron los principales actores sociales, especialmente a principios de la fase de desarrollo de un nuevo léxico. La dimensión transnacional de su historia fue significativa. Los familiares forjaron un lenguaje de la experiencia no solo dentro de Chile sino también en diálogo con grupos hermanos en el extranjero. Víctimas-sobrevivientes en la búsqueda de familiares y de la verdad enfrentaban una agonía similar en otras partes de América Latina. En 1981 la AFDD de Chile se reunió con organizaciones hermanas en París, San José (Costa Rica) y Caracas para experimentar una solidaridad más amplia, reflexionar y debatir el futuro, y construir una voz y una estrategia más fuertes. Fundaron una federación transnacional, la Federación Latinoamericana de Asociaciones de Familiares de Detenidos Desaparecidos (Fedefam). Los encuentros marcaron una nueva fase en la dialéctica de la acción social y del análisis reflexivo - y en el desarrollo de un lenguaje de experiencia-.

La memoria como tal comenzó a ser destacada como un valor de gran importancia para los derechos humanos y la lucha contra la dictadura. América Latina había dado lugar a un nuevo tipo de dictadura militar: una dictadura comprometida no a entrar con una represión de corto plazo para restaurar el orden, sino más bien a crear un nuevo orden. El nuevo esquema significaba borrar para siempre las demandas sociales de sectores populares de la sociedad y las ideas políticas vinculadas a esas demandas. Las detenciones misteriosas de personas que desaparecieron sin dejar rastro, como si nunca hubieran existido, 
fue una técnica crítica en el proyecto de reeducación y supresión. La represión y el miedo sirvieron como instrumentos inmediatos de dominación. A la larga, sin embargo, el punto era controlar la memoria. Las nuevas dictaduras "coordinaron dos ejes fundamentales: el terrorismo de Estado, amenaza a nivel táctico; y el borramiento de toda la memoria histórica en un nivel estratégico, limpiando la pizarra del pasado, buscando hundir a la gente en el olvido de sí misma”13.

En un sentido real, los familiares de la AFDD y otros en el campo de los derechos humanos, dentro y fuera de Chile, descubrieron la memoria. Sin embargo, rastrear cómo, más allá del momento de crisis y replanteamiento de finales de los años setenta y principios de la década de los ochenta, la memoria se arraigó como un fenómeno cultural más amplio excede los límites de este ensayo. Basta decir que las luchas sobre cómo recordar hechos cruciales y su significado más amplio confluyeron con los disturbios de las protestas masivas contra la dictadura en la década de los ochenta. En el plebiscito de 1988 para extender el gobierno de Pinochet, el ejercicio de autorratificación del régimen militar fracasó y lo obligó a negociar una transición; en ese momento el lenguaje de la memoria contra el olvido había adquirido una firme resonancia simbólica. El 29 de agosto de 1988, justo antes del anuncio oficial de que Pinochet se mantendría firme como el candidato del "sí" en el plebiscito, mil activistas de Mujeres por la Vida, divididas en cuarenta equipos de veinticinco personas, convergieron repentinamente en diez calles peatonales del centro de Santiago durante la hora del almuerzo, llevando misteriosos paquetes. Desempacaron siluetas de tamaño real, cada una de las cuales representaba a una persona y también la urgencia de la pregunta por la memoria. Colocaron las gigantes siluetas negras contra paredes, puertas y bancos de la calle antes de fundirse nuevamente en el paisaje urbano. En cada figura aparecía, en grandes letras blancas, el nombre de una víctima específica. La persona ausente pero presente preguntaba: “¿Me olvidaste?”. Debajo de la pregunta se podía elegir: "sí/no”. Esto creó un paralelo con la opción que se daba en el plebiscito ${ }^{14}$.

Consultado originalmente en Archivo Sergio Insunza, Desaparecidos, "Acta Final" del I Congreso Latinoamericano de Familiares de Desaparecidos, San José, Costa Rica, enero 20-23, 1981, 2-4, caja 1, leg. 2. Después del 2010, el Archivo Insunza fue trasladado de la Fundación Salvador Allende hacia el Museo de la Memoria y los Derechos Humanos. 


\section{Conclusión}

Tenemos aquí, entonces, una historia curiosa. Una lucha sobre cómo recordar ya había iniciado durante la crisis de 1973. Salvador Allende entendió esto el 11 de septiembre, el día que se despidió y los militares bombardearon el palacio presidencial en el corazón de Santiago. Pero el lenguaje de la memoria como un grito de guerra, como una experiencia y un valor preciado aún no había llegado. La lucha por la memoria precedió a la memoria. La palabra clave que resultó influyente, obstinada y contenciosa durante la transición democrática de las décadas de 1990 y 2000 no se cristalizó hasta finales de los setenta y principios de los ochenta. Pero esa fue una fase embrionaria, algo gelificante dentro del asediado campo de los derechos humanos. La palabra clave no ganó mucha tracción hasta los tiempos de las protestas callejeras masivas y acciones de desobediencia civil que sacudieron al régimen durante 1983-1988 y que finalmente forzaron una transición en 1990. Irónicamente, memoria como código cultural, como un lenguaje de experiencia y lucha continua, no se convirtió en una noción de sentido común ampliamente reconocible hasta la transición misma.

La historicidad de la memoria como palabra clave es importante por varias razones. Primero, muestra que encontrar un lenguaje para describir y confrontar la atrocidad fue una experiencia de aprendizaje, un descubrimiento forjado en el crisol de las luchas de vida y muerte, y su legado inacabado. El proceso fue dinámico, experiencial y experimental. Más que la aplicación del lenguaje cultural disponible para una nueva situación, la palabra clave condensaba la dialéctica de la lucha callejera y la lucha cognitiva.

En segundo lugar, precisamente porque el terror estatal inflige no solo violencia sino negación y eufemismo - una "historia oficial" - , la lucha por un nuevo lenguaje de verdad atestigua el valor del análisis holístico de la política y la cultura. Cómo un nuevo clima social y un nuevo vocabulario de verdad surgen y se vuelven influyentes no es un asunto que se reduzca al diseño o a la acción del Estado. Es en la interacción de la acción cultural y política, tanto por parte de los actores de la sociedad civil como de los actores estatales, que podemos rastrear el surgimiento de un nuevo lenguaje de la experiencia.

En el caso chileno, los actores estatales siempre tuvieron un gran interés en moldear la memoria de 1973. La Junta y sus partidarios comenzaron describiendo la crisis de 1973 como una historia de salvación que valía la pena recordar: el rescate del pueblo chileno del caos económico y del inminente baño de sangre por parte de la izquierda. Cuando el campo emergente de familiares, sobrevivientes, activistas, personas de conciencia y otros partidarios de los derechos humanos 
empujó al primer plano la realidad negada de la atrocidad masiva, y cuando su impulso coincidió con otras tensiones, la cuestión de la memoria —qué y cómo recordar, y por qué- se volvió explosiva. La Junta decretó su amnistía de 1978 y avanzó hacia un lenguaje del olvido - olvido deliberado-como un hecho positivo. El pasado era el pasado y había llegado el momento de mirar hacia adelante. Pero, como hemos visto, el régimen fracasó en crear un lenguaje perfecto del olvido. Por el contrario, la política de olvido deliberado provocó una nueva fase de crisis y acción directa, reflexión, trabajo en red, estrategia y el desarrollo del lenguaje por parte de familiares de desaparecidos y sus aliados. Lo que el régimen logró a la larga no fue el lenguaje hegemónico del olvido sino un lenguaje de antítesis: memoria versus olvido.

Aunque la memoria como palabra clave surgiría con mayor fuerza durante la transición democrática posterior a 1990, ese recorrido tampoco fue un desarrollo lineal diseñado por el Estado. Críticos de la sociedad civil, importantes para la legitimidad moral y política de la coalición de centro-izquierda, denunciaron la retirada de las iniciativas de derechos humanos después de los primeros años de transición y presionaron contra lo limitado de las iniciativas del Estado que tuvieron lugar. La dialéctica del Estado y la sociedad civil, respaldada por iniciativas transnacionales, incluido el arresto de Pinochet en Londres en 1998, terminaron produciendo nuevas iniciativas y un nuevo lenguaje. Con el tiempo, la "memoria" y los "derechos humanos" se hicieron inseparables, una realidad cultural consagrada en el nombre del museo estatal, Museo de la Memoria y los Derechos Humanos, inaugurado en el 2010.

Que la "memoria" tiene una historia, más que un significado que es evidente o transhistórico, importa por una tercera razón. La memoria es en parte una historia política y cultural de una generación. Mientras la memoria siga siendo un tema de discordia - una palabra para insistir, una experiencia demasiado formativa y traumática para ser olvidada, un grito de que el pasado en el presente sigue siendo injusto y aún requiere remedio-, cada generación de los activistas sociales pondrá su propio sello en la palabra clave. De lo contrario, la memoria se osifica en nostalgia y termina en el basurero de la cultura y la política. En años recientes, las protestas de indígenas mapuches por el impacto de la industria de exportación forestal en la tierra y las aguas en el sur y las protestas de estudiantes universitarios contra la educación privatizada y la aplastante deuda han sacudido a Chile. Con estas luchas ha tenido lugar una cierta resignificación de la memoria.

Los activistas mapuches han extendido las líneas de tiempo relevantes hacia atrás y hacia adelante para incluir no solo las atrocidades de la dictadura de 
Pinochet sino también los despojos que reconfiguraron el sur desde finales del siglo XIX y la continuación del abuso violento y la injusticia en la era de la posdictadura. Los estudiantes han redefinido el legado del régimen de Pinochet que requiere una reparación urgente en el presente para incluir las atrocidades violentas contra el cuerpo y la mente, así como la reestructuración de la educación bajo la dictadura. El nuevo sistema golpea duramente las oportunidades socioeconómicas al tiempo que consagra el principio de ganancia. En este cambiante contexto generacional, el significado del 11 de septiembre de 1973, su memoria, ha atraído nuevos reclamos y nuevos actores sociales. El 9/11 chileno ejerce una continua energía cultural.

Traducción de Silvia Monroy Álvarez

Universidad del Cauca, Popayán

\section{Referencias}

Ahumada, Eugenio, Rodrigo Atria, Javier Luis Egaña, Augusto Góngora, Carmen Quesney, Gustavo Saball y Gustavo Villalobos. 1989. Chile: la memoria prohibida. Las violaciones a los derechos humanos 1973-1983. Santiago de Chile: Pehuén.

Bartov, Omer. 2000. Mirrors of Destruction: War, Genocide, and Modern Identity. Nueva York: Oxford University Press.

Colectivo de Memoria Histórica Corporación José Domingo Cañas. 2005. Tortura en poblaciones del Gran Santiago (1973-1990). Santiago de Chile: Corporación José Domingo Cañas.

Degregori, Carlos Iván. 2012. How Difficult is to Be God: Shining Path's Politics of War in Peru, 1980-1999. Madison: University of Wisconsin Press.

Dinges, John. 2004. The Condor Years: How Pinochet and His Allies Brought Terrorism to Three Continents. Nueva York: New Press.

Franco, Jean. 2013. Cruel Modernity. Durham, NC: Duke University Press.

Guzmán, Patricio. 1998. Chile: la memoria obstinada. Nueva York: Icarus Films. Largometraje, 58:33, DVD.

Huneeus, Alexandra. 2013. "International Criminal Law by Other Means: The Quasi-criminal Jurisdiction of the Human Rights Courts”. American Journal of International Law 107 (1): 1-44. https://doi.org/10.5305/amerjintelaw.107.1.0001

Jelin, Elizabeth. 2002. Los trabajos de la memoria. Madrid: Siglo XXI.

Keck, Margaret E. y Kathryn Sikkink. 1998. Activists beyond Borders: Advocacy Networks in International Politics. Ithaca, NY: Cornell University Press. 
Milton, Cynthia, ed. 2014. Art from a Fractured Past: Memory and Truth-Telling in Post-Shining Path Peru. Durham: Duke University Press.

Sikkink, Kathryn. 2011. The Justice Cascade: How Human Rights Prosecutions Are Changing World Politics. Nueva York: Norton.

Stern, Steve J. (1998) 2004. Remembering Pinochet's Chile: On the Eve of London. Durham, NC: Duke University Press.

-. 2006. Battling for Hearts and Minds: Memory Struggles in Pinochet's Chile, 1973-1988. Durham, NC: Duke University Press.

-. 2010. Reckoning with Pinochet: The Memory Question in Democratic Chile, 1989-2006. Durham, NC: Duke University Press.

Stern, Steve J., Peter Winn, Federico Lorenz y Aldo Marchesi. 2013. No hay mañana sin ayer. Batallas por la memoria histórica en el Cono Sur. Lima: Instituto de Estudios Peruanos.

Thompson, Edward Palmer. 1978. "Eighteenth-Century English Society: Class Struggle without Class?”. Social History 3 (2): 133-165. http://www.jstor.org/stable/4284798

Todorov, Tzvetan. 2002. Memoria del mal, tentación del bien: indagación sobre el siglo XX. Barcelona: Península. 